\title{
Glycosylated haemoglobin in chronic renal failure and after renal transplantation
}

\author{
D FREEDMAN, P DANDONA, O FERNANDO, JF MOORHEAD \\ From the Metabolic Unit, Department of Chemical Pathology, and the Department of Nephrology and \\ Transplantation, Royal Free Hospital, Pond Street, London NW3 2QG
}

SUMmARY Haemoglobin $\mathrm{A}_{1}\left(\mathrm{HbA}_{1}\right)$ was determined by ion-exchange chromatography in 37 normoglycaemic patients with chronic renal failure (CRF) and 26 with successful renal transplants. Blood glucose concentrations in patients with CRF were similar to those in controls, and there.was a significant correlation between fasting blood glucose concentration and $\mathrm{Hb}_{1}$ in these groups. $\mathrm{HbA}_{1}$ in patients with $\mathrm{CRF}$ was, however, significantly lower than that in control subjects. Concentrations of $\mathrm{HbA}_{1}$ in patients on haemodialysis, peritoneal dialysis, and those with steady state CRF prior to dialysis were not significantly different from each other. Whereas patients with successful renal transplants of greater than 3 months' duration had $\mathrm{HbA}_{1}$ concentrations indistinguishable from controls, $\mathrm{HbA}_{1}$ in patients with transplants of shorter duration were significantly lower. These observations are suggestive of a shortened erythrocyte survival in CRF per se. Furthermore, these results indicate: (a) the inadequacy of $\mathrm{HbA}_{1}$ in monitoring the quality of diabetic control in patients with CRF, and (b) the absence of a specific effect of dialysis on $\mathrm{HbA}_{1}$, and the restoration to normal of $\mathrm{HbA}_{1}$ after successful renal transplantation.

Haemoglobin $A_{1}\left(H_{b} A_{1}\right)$ has previously been shown in a preliminary study to be significantly lower in patients with CRF than in controls. ${ }^{\prime}$ Since the $\mathrm{HbA}_{1}$ content of any erythrocyte is dependent on the duration of glycosylation-that is, life span of the erythrocyte and the rate of glycosylation-that is, the concentration of plasma glucose, ${ }^{2}$ it follows that a diminution of $\mathrm{HbA}_{1}$ in euglycaemic patients is suggestive of shortened erythrocyte survival. Previous studies using ${ }^{51} \mathrm{Cr}$-labelled red blood cells (RBC) have also shown a shortened erythrocyte survival in patients with CRF. ${ }^{3}$

We have now attempted to answer the questions (i) whether the low $\mathrm{HbA}_{1}$ and shortened survival of erythrocytes are secondary to CRF per se or to long term haemodialysis; (ii) whether $\mathrm{HbA}_{1}$ in peritoneally dialysed and haemodialysed patients are significantly different and (iii) whether successful transplantation restores $\mathrm{HbA}_{1}$ to normal.

\section{Patients and methods}

The following groups of patients were studied:

Group 1 Patients $(\mathrm{n}=8)$ with low creatinine clearance $(\mathrm{Cr} \mathrm{cl}<20 \mathrm{ml} / \mathrm{min})$ on dietary restriction but no dialysis treatment (mean plasma glucose $=4.4 \mathrm{mmol} /$ l).

Accepted for publication 9 December 1981
Group 2 Patients $(\mathrm{n}=10)$ with CRF $(\mathrm{Cr} \mathrm{cl}<10$ $\mathrm{ml} / \mathrm{min}$ ) on peritoneal dialysis for duration of more than 1 month (mean plasma glucose $=4.6 \mathrm{mmol} / \mathrm{l}$ ).

Group 3 Patients $(\mathrm{n}=19)$ with CRF (age range 10 to 53 years, mean 34 years) on long-term haemodialysis for duration of more than 2 months' (mean plasma glucose $=4.0 \mathrm{mmol} / \mathrm{l}$ ).

Group 4 Patients $(\mathrm{n}=6)$ with recent renal transplants less than 3 months' duration ( $\mathrm{Cr}$ cl 10 to 53 $\mathrm{ml} / \mathrm{min}$ ) (mean plasma glucose $=4.5 \mathrm{mmol} / \mathrm{l}$ ).

Group 5 Patients $(\mathrm{n}=20)$ with successful renal transplants greater than 3 months' duration $(\mathrm{Cr}$ cl 25 to $120 \mathrm{ml} / \mathrm{min}$ ) (mean plasma glucose $=3.9 \mathrm{mmol} / \mathrm{l})$.

Group 6 Control group $(\mathrm{n}=17)$ (mean plasma glucose $4.2 \mathrm{mmol} / \mathrm{l})$.

None of these patients had fasting or post prandial hypoglycaemia, hyperglycaemia, glycosuria or hypoglycaemia.

Blood samples were collected in heparin and were stored in a refrigerator at $4^{\circ} \mathrm{C}$ before $\mathrm{HbA}_{1}$ measurement. All estimations were carried out within three days of collection of the sample. Haemoglobin $A_{1}$ was measured by a kit (Isolab Laboratories) with 


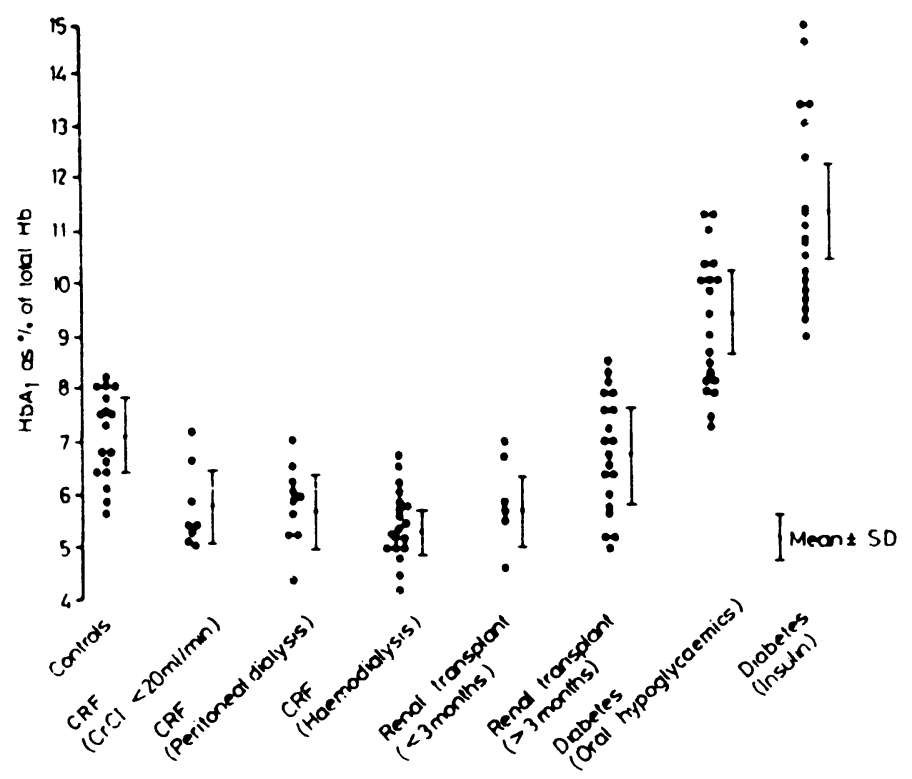

Fig. 1 Graph showing $H b A$ values in patients with chronic renal failure. $H b A_{1}$ values in diabetic patients, with normal renal function, are shown for comparison.

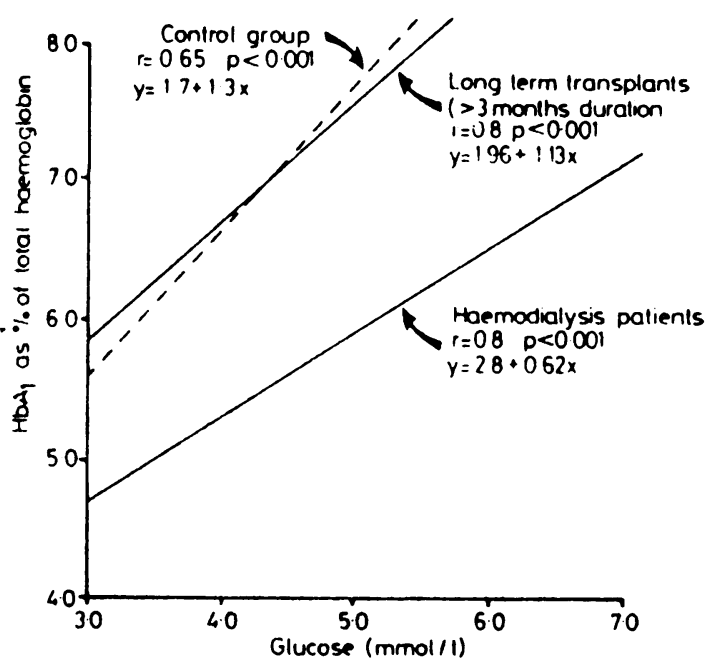

Fig. 2 Correlation between glucose in mmolll and $\mathrm{Hb} \mathrm{A}_{1}$ concentrations in haemodialysis patients, long term-transplants and controls.

chromatographic separation of $\mathrm{HbA}_{1}$ from $\mathrm{HbA}$ on a biorex microcolumn at constant temperatures of $22.5^{\circ} \mathrm{C}$ in an incubator. ${ }^{4}$ All $\mathrm{HbA}_{1}$ results were expressed as percentage of total haemoglobin and not absolute concentrations.

\section{Results}

$\mathrm{HbA}_{1} \%$ in patients with CRF prior to dialysis was $5.8 \pm 0.7$ (mean $\pm \mathrm{SD}$ ); this was significantly lower than that in controls (mean $\pm \mathrm{SD}=7.3 \pm 0.7 \%$; $<0.001)$ although the mean blood glucose in two groups was similar $(4.4 \mathrm{mmol} / / v 4.2 \mathrm{mmol} / \mathrm{l})$ (Fig. 1). $\mathrm{HbA}_{1} \%$ in patients on haemodialysis (mean $\pm \mathrm{SD}=5.3 \pm 0.4$ ) and peritoneal dialysis (mean $\pm \mathrm{SD}=5 \cdot 7 \pm 0 \cdot 7$ ) was not significantly different from that in patients with CRF prior to dialysis. There was no significant differerıe in $\mathrm{HbA}_{1} \%$ between the two dialysis groups.

In patients with transplants of less than 3 months' duration $\mathrm{HbA}_{1} \%$ (mean $\pm \mathrm{SD}=5.7 \pm 0.7$ ) was similar to that in patients with CRF and was significantly lower than that in controls $(p<0.01)$. $\mathrm{HbA}_{1} \%$ in patients with successful renal transplants of longer duration (mean $\pm \mathrm{SD}=6.8 \pm 1.0$ ) was significantly greater than that in patients with CRF $(\mathrm{p}<0.01)$ and those with recent transplants $(\mathrm{p}<$ $0.01)$; it was not significantly different from that in controls. There was a significant correlation between blood glucose concentration and $\mathrm{HbA}_{1} \%$ in patients on haemodialysis $(r=0 \cdot 8)$, those with long term transplants $(r=0.8)$ and in controls $(r=0.65)$ (Fig. 2). Patients on long-term haemodialysis had lower $\mathrm{HbA}_{1} \%$ for a given blood glucose concentration that when compared with normal subjects and there was no overlap between the two groups $(p<0.05$, Student's unpaired $t$ test). 


\section{Discussion}

It is clear from our observations that $\mathrm{CRF}$ is associated with markedly lower $\mathrm{HbA}_{1} \%$ without a concomitant change in blood glucose concentrations. Successful renal transplantation in the long term restores $\mathrm{HbA}_{1} \%$ to concentrations similar to those observed in normal subjects. It is of interest that in our series blood glucose concentrations in various patient groups were not significantly different from controls. This allows us to make valid comparisons of $\mathrm{HbA}_{1} \%$ in different groups.

Thus, the restoration of normal $\mathrm{HbA}_{1} \%$ in transplanted patients does not appear to be the consequence of steroid therapy. Indeed, this normalisation of $\mathrm{HbA}_{1} \%$ occurs at a stage when the dose of steroids is relatively low. The reason why it takes approximately three months for the normalisation of $\mathrm{HbA}_{1}$ to occur is probably due to the time taken for pretransplantation RBCs with low $\mathrm{HbA}_{1}$ to be replaced by a new population of RBCs with a normal survival and hence a normal $\mathrm{HbA}_{1}$ content.

Apart from indicating that $\mathrm{HbA}_{1} \%$ would be an unreliable index of glucose homeostasis in patients with advanced diabetic nephropathy or CRF due to any other cause, our observations have interesting haematological implications.

The diminished $\mathrm{HbA}_{1} \%$ in uraemic patients without an alteration in blood glucose concentrations is consistent with a shortened RBC survival in these patients. However, it is surprising that $\mathrm{HbA}_{1} \%$ in patients on haemodialysis was not significantly different either from that in uraemic patients prior to dialysis or that in patients on peritoneal dialysis. This suggests that the main cause of shortened RBC survival in patients with CRF is uraemia and not haemodialysis.

In conclusion, $\mathrm{CRF}$ is associated with a reduction of $\mathrm{HbA}_{1}$ irrespective of dialysis treatment or its mode. This reduction in $\mathrm{HbA}_{1}$ is restored to normal after successful renal transplantation. These observations may have important implications in terms of erythrocyte survival and the assessment of glycaemic control in CRF.

The authors wish to thank Mrs M Elleman for secretarial assistance.

\section{References}

' Dandona P, Freedman DB, Moorhead J. Glycosylated $\mathrm{Hb}$ in chronic renal failure. Br Med J 1979;i:1183-4.

${ }^{2}$ Bunn HF, Gabbay KH, Gallop PM. The glycosylation of haemoglobin: relevance to diabetes mellitus. Science 1978;200:21-3.

${ }^{3}$ Stewart JH. Haemolytic anaemia in acute and chronic renal failure. $Q$ J Med 1967;36:85-105.

4 Abraham EC, Huff TA, Cope ND, Wilson JB, Bransome ED, Huisman THJ. Determination of glycosylated haemoglobins $\left(\mathrm{HbA}_{1}\right)$ with a new microcolumn procedure. Diabetes 1978;27:931-7.

Requests for reprints to: Dr P Dandona, Metabolic Unit, Department of Chemical Pathology, Royal Free Hospital, London NW3 2QG, England. 